\section{Analysis of Genetic Diversity in Chrysopogon aciculatus Using Intersimple Sequence Repeat and Sequence-related Amplified Polymorphism Markers}

\author{
Xinyi Zhang, Li Liao, and Zhiyong Wang ${ }^{1}$ \\ Key Laboratory of Protection and Developmental Utilization of Tropical \\ Crop Germplasm Resources, Ministry of Education/College of Agriculture, \\ Hainan University, Haikou, Hainan 570228, China
}

\section{Changjun Bai}

Tropical Pasture Research Center, Chinese Academy of Tropical Agricultural Sciences, Danzhou, Hainan 571700, China

\author{
Jianxiu Liu \\ Institute of Botany, Jiangsu Province and Chinese Academy of Sciences, \\ Jiangsu, Nanjing 210014, China
}

Additional index words. genetic relationship, UPGMA, cluster analysis, intersimple sequence repeat, sequence-related amplified polymorphism

\begin{abstract}
Molecular genetic diversity and relationships among 86 Chrysopogon aciculatus (Retz.) Trin. accessions were assessed using intersimple sequence repeat (ISSR) and sequence-related amplified polymorphism (SRAP) markers. Twenty-five ISSR markers generated 283 amplification bands, of which 266 were polymorphic. In addition, 576 polymorphic bands were detected from 627 bands amplified using 30 SRAP primers. Both marker types revealed a high level of genetic diversity, with ISSR markers showing a higher proportion of polymorphic loci (PPL; 94\%) than SRAP markers (91.87\%). The ISSR and SRAP data were significantly correlated $(r=\mathbf{0 . 8 0 2 3})$. Cluster analysis of the separate ISSR and SRAP data sets clustered the accessions into three groups, which generally were consistent with geographic provenance. Cluster analysis of the combined ISSR and SRAP data set revealed four major groups similar to those based solely on ISSR or SRAP markers. The findings demonstrate that ISSR and SRAP markers are reliable and effective tools for analysis of genetic diversity in $C$. aciculatus.
\end{abstract}

The perennial grass genus Chrysopogon is mainly distributed in tropical and subtropical regions of the world. Three species are indigenous to China: Chrysopogon echinulatus (Nees ex Steud.) Will. Watson, Chrysopogon orientalis A. Camus, and Chrysopogon aciculatus. C. aciculatus is the only member of the genus suitable for use as a turfgrass. The species is drought and shade tolerance, and shows low maintenance requirements. $C$. aciculatus is widely distributed in southern China and commonly used in lawns, sports fields, and shaded turf (Zheng et al., 2005).

The development and application of DNAbased molecular markers has revolutionized

\footnotetext{
Received for publication 26 May 2016. Accepted for publication 23 June 2016.

This work was supported by the National Natural Science Foundation of China (31260489).

We thank three anonymous reviewers for useful comments and suggestions to improve the manuscript.

${ }^{1}$ Corresponding author. E-mail: wangzhiyong7989@ 163.com.
}

the study of genetic diversity (Kalendar et al., 2011). DNA-based molecular markers are often simple to amplify and rapidly operable. Such markers have been widely used for research into interspecific and intraspecific genetic diversity among turfgrasses. Commonly used molecular marker technologies include random amplified polymorphic DNA (RAPD), amplified fragment length polymorphisms (AFLPs), and simple sequence repeats (SSRs) (Kalia et al., 2011). Intersimple sequence repeat markers can be amplified simply and directly without knowledge of the flanking sequences, thus enabling easier development of specific primers compared with SSR markers. The development costs for ISSR markers are low, and ISSR markers show higher reproducibility and reliability compared with AFLP and RAPD markers (Barth et al., 2002; Huang et al., 2013; Zietkiewicz et al., 1994). ISSR technology has been widely used in genetic diversity analysis (Baliyan et al., 2014; Biswas et al., 2010; Djè et al., 2010; Tao et al., 2014; Wang et al., 2013) and DNA fingerprinting (Huang et al., 2010; Kalpana et al., 2012; Reunova et al., 2010; Smolik et al., 2010;
Zietkiewicz et al., 1994). The SRAP technique is based on polymerase chain reaction (PCR) amplification. SRAP primers are designed on the basis that exons are GC rich whereas promoters and introns are AT rich; the polymorphism reflects fundamental variation in the lengths of introns, promoters, and intergenic spacers, both among individuals and among species ( $\mathrm{Li}$ and Quiros, 2001). The unique primer designs used in the SRAP technique allow direct amplification of open reading frames in the genome, regardless of flanking sequence (Budak et al., 2004a; Wang et al., 2009a). SRAP technology has been widely used in population genetic analysis, paternity testing, genome mapping, and marker-assisted selection. The technique has numerous advantages over other molecular marker technologies, such as abundant polymorphism, high reproducibility, easy amplification, and good stability (Babaei et al., 2014; Budak et al., 2004a; Cai et al., 2011; Li and Quiros, 2001; Uzun et al., 2009). Combination of ISSR and SRAP markers has been used for assessment of genetic diversity among diverse species, such as Dianthus L. species and Salvia miltiorrhiza Bunge (Budak et al., 2004a; Li et al., 2014; Liu et al., 2008; Song et al., 2010; Yildiz et al., 2011; Yilmaza et al., 2012).

Previous studies of variability within $C$. aciculatus have mainly focused on morphological characteristics (Clarkson, 1992; Liao et al., 2011; Zheng et al., 2005), with no information available on genetic diversity using molecular markers. In this study, we collected 86 C. aciculatus accessions from five provinces in China with the aim to evaluate the genetic diversity among the accessions and to assess the level of polymorphism detectable by the use of ISSR and SRAP markers.

\section{Materials and Methods}

Plant materials. Eighty-six C. aciculatus accessions were collected from the Hainan, Guangxi, Guangdong, Fujian, and Yunnan provinces of China (Table 1). The accessions were grown under field conditions at the Agronomy Garden, Hainan University, Haikou, Hainan, China $\left(20^{\circ} 03^{\prime} \mathrm{N}, 110^{\circ} 19^{\prime} \mathrm{E}\right.$; $69.8 \mathrm{~m}$ above sea level). This area experiences a tropical monsoon climate. The average annual rainfall is $900-2200 \mathrm{~mm}$ and average annual sunlight hours exceed $2000 \mathrm{~h}$. The temperature ranges from 9.4 to $38.7^{\circ} \mathrm{C}$, with an annual average of $23.8{ }^{\circ} \mathrm{C}$. Detailed information for each collection provenance is provided in Table 1.

For each accession, 40 healthy stolons with two internodes of one accession were transplanted into separate $0.25-\mathrm{m}^{2}$ plot, with $50-\mathrm{cm}$ spacing between each plot. Each plot was trimmed weekly to prevent interplot contamination. The plots were frequently mowed to a height of $50 \mathrm{~mm}$. In accordance with the methods of Zheng et al. (2005), routine irrigation, fertilization, and fungicide application were performed to ensure active and healthy growth of the accessions.

DNA extraction. Genomic DNA of each accession was extracted from healthy, fresh, 
Table 1. Eighty-six Chrysopogon aciculatus samples collected from different locations in China and used in the study.

\begin{tabular}{|c|c|c|c|c|c|}
\hline No. & Accession no. & Origin & No. & Accession no. & Origin \\
\hline 1 & CA01 & Haikou, Hainan & 44 & CA46 & Qiongzhong, Hainan \\
\hline 2 & $\mathrm{CA} 02$ & Qionghai, Hainan & 45 & CA47 & Longzhou, Guangxi \\
\hline 3 & CA03 & Dongfang, Hainan & 46 & CA48 & Chongzuo, Guangxi \\
\hline 4 & CA04 & Sanyai, Hainan & 47 & CA49 & Pinghe, Fujian \\
\hline 5 & CA05 & Qionghai, Hainan & 48 & CA50 & Wengyuan, Guangxi \\
\hline 6 & CA06 & Changjiang, Hainan & 49 & CA51 & Lingao, Hainan \\
\hline 7 & CA07 & Guigang, Guangxi & 50 & CA52 & Guiping, Guangxi \\
\hline 8 & CA08 & Qionghai, Hainan & 51 & CA53 & Qinzhou, Guangxi \\
\hline 9 & CA09 & Wanning, Hainan & 52 & CA54 & Beihai, Guangxi \\
\hline 10 & CA10 & Haikou, Hainan & 53 & CA55 & Hepu, Guangxi \\
\hline 11 & CA11 & Baishau, Hainan & 54 & CA56 & Hepu, Guangxi \\
\hline 12 & CA12 & Danzhou, Hainan & 55 & CA57 & Hepu, Guangxi \\
\hline 13 & CA14 & Dingan, Hainan & 56 & CA58 & Wuzhishan, Hainan \\
\hline 14 & CA15 & Danzhou, Hainan & 57 & CA59 & Qiongzhong, Hainan \\
\hline 15 & CA16 & Dongfang, Hainan & 58 & CA60 & Wuzhishan, Hainan \\
\hline 16 & CA18-1 & Danzhou, Hainan & 59 & CA61 & Wuzhishan, Hainan \\
\hline 17 & CA18-2 & Danzhou, Hainan & 60 & CA62 & Qiongzhong, Hainan \\
\hline 18 & CA19 & Qiongzhong, Hainan & 61 & CA63 & Wuzhou, Guangxi \\
\hline 19 & CA20 & Wanning, Hainan & 62 & CA64 & Yingde, Guangdong \\
\hline 20 & $\mathrm{CA} 21$ & Dingan, Hainan & 63 & CA65 & Wuzhou, Guangxi \\
\hline 21 & CA22 & Qionghai, Hainan & 64 & CA66 & Qiongzhong, Hainan \\
\hline 22 & CA23 & Qionghai, Hainan & 65 & CA67 & Shanghang, Fujian \\
\hline 23 & CA24 & Sanya, Hainan & 66 & CA68 & Wuzhou, Guangxi \\
\hline 24 & CA25 & Cenxi, Guangxi & 67 & CA69 & Hepu, Guangxi \\
\hline 25 & CA26 & Yingde, Guangdong & 68 & CA70 & Xuwen, Guangdong \\
\hline 26 & CA27 & Danzhou, Hainan & 69 & CA71 & Maoming, Guangdong \\
\hline 27 & CA28 & Qiongzhong, Hainan & 70 & CA72 & Bobai, Guangxi \\
\hline 28 & CA29 & Chenxi, Guangxi & 71 & CA73 & Suixian, Guangdong \\
\hline 29 & CA31 & Qiongzhong, Hainan & 72 & CA74 & Hepu, Guangxi \\
\hline 30 & CA32 & Laibin, Guangxi & 73 & CA75 & Puer, Yunnan \\
\hline 31 & CA33 & Zhaoqing, Guangdong & 74 & CA76 & Zhenyuan, Yunnan \\
\hline 32 & CA34 & Tunchang, Hainan & 75 & CA77 & Ninger, Yunnan \\
\hline 33 & CA35 & Mangshi, Yunnan & 76 & CA78 & Lianjiang, Guangdong \\
\hline 34 & CA36 & Changtai, Fujian & 77 & CA79 & Xuwen, Guangdong \\
\hline 35 & CA37 & Wenchang, Hainan & 78 & CA80 & Suixi, Guangxi \\
\hline 36 & CA38 & Lingshui, Hainan & 79 & CA81 & Lingao, Hainan \\
\hline 37 & CA39 & Beihai, Guangxi & 80 & CA82 & Lingao, Hainan \\
\hline 38 & CA40 & Tunchang, Hainan & 81 & CA84 & Chengmai, Hainan \\
\hline 39 & CA41 & Haikou, Hainan & 82 & CA85 & Haikou, Hainan \\
\hline 40 & CA42 & Haikou, Hainan & 83 & CA86 & Haikou. Hainan \\
\hline 41 & CA43 & Qiongzhong, Hainan & 84 & CA87 & Sanya, Hainan \\
\hline 42 & CA44 & Longzhou, Guangxi & 85 & CA88 & Qionghai, Hainan \\
\hline 43 & CA45 & Daxin, Guangxi & 86 & CA89 & Wanning, Hainan \\
\hline
\end{tabular}

young leaf tissue using the cetyltrimethylammonium bromide method (Doyle and Doyle, 1987). DNA concentrations were determined by electrophoresis in $1.5 \%$ agarose gel by comparison with a sample of known concentration. Genomic DNA was diluted to a final concentration of $30 \mathrm{ng} \cdot \mu \mathrm{L}^{-1}$ and stored at $-20{ }^{\circ} \mathrm{C}$ until required.

ISSR analysis. Twenty-five ISSR primers were chosen from 100 primers supplied by Invitrogen Biotech Co. (Shanghai, China) to amplify polymorphisms in the $86 \mathrm{C}$. aciculatus accessions. Detailed primer information is given in Table 2. The amplification procedure followed the protocol established by Wang et al. (2009a). Each PCR mixture (total volume $20 \mu \mathrm{L}$ ) consisted of $2 \mu \mathrm{L} 10 \times$ buffer [100 mm Tris- $\mathrm{HCl}(\mathrm{pH} 8.3), 500 \mathrm{~mm} \mathrm{KCl}$, and $15 \mathrm{~mm} \mathrm{MgCl}_{2}$ ], $2.5 \mathrm{~mm}$ dNTPs (Invitrogen), $0.2 \mu \mathrm{M}$ primer (Invitrogen), $0.2 \mu \mathrm{L}$ Taq DNA polymerase (Takara Biotechnology, Dalian, China), $14 \mu \mathrm{L} \mathrm{ddH}_{2} \mathrm{O}$, and $\approx 60 \mathrm{ng}$ template DNA. Amplifications were carried out in a PTC-200 ${ }^{\mathrm{TM}}$ Thermal Cycler (MJ Research, Watertown, MA) using the following PCR program: initial denaturation at $95{ }^{\circ} \mathrm{C}$ for primer, $0.2 \mu \mathrm{L}$ Taq DNA polymerase, $13.3 \mu \mathrm{L}$ $\mathrm{ddH}_{2} \mathrm{O}$, and $\approx 30 \mathrm{ng}$ template DNA. Amplifications were performed in a PTC-200 ${ }^{\mathrm{TM}}$ Thermal Cycler using the following PCR program: $4 \mathrm{~min}$ denaturation at $94{ }^{\circ} \mathrm{C}$, $1 \mathrm{~min}$ degeneration at $94{ }^{\circ} \mathrm{C}, 1 \mathrm{~min}$ annealing at $37^{\circ} \mathrm{C}$, and $10 \mathrm{~s}$ elongation at $72{ }^{\circ} \mathrm{C}$. In the following 35 cycles, the annealing temperature was increased to $50{ }^{\circ} \mathrm{C}$, with a final elongation step of $7 \mathrm{~min}$ at $72^{\circ} \mathrm{C}$. PCR amplicons were fractionated on $8.0 \%$ nondenatured polyacrylamide gels using a Hoefer vertical gel apparatus at 200 $\mathrm{V}$ for $2.5 \mathrm{~h}$ in $1 \times$ Tris/borate/EDTA buffer. A 100-bp DNA ladder (Dye Plus) was used as a reference for estimation of allele sizes. After electrophoresis, the gel was subjected to rapid silver staining for detection of DNA bands (Wang et al., 2009b)

Data analysis. The presence or absence of each SRAP or ISSR fragment was coded as 1 or 0 , respectively. Popgene version 1.32 was used to calculate Nei's gene diversity (He) (Nei, 1973) and Shannon's information index $(I)$ (Shannon and Weaver, 1949), which were used to compute Nei's standard genetic distance coefficients (Nei and Li, 1979) for the 86 accessions. The resulting distance matrix was used to construct a dendrogram with the unweighted pair-group method with arithmetic averages (UPGMA) (Sneath and Sokal, 1973) using NTSYS-pc version 2.10s software. The correlation between similarity matrices generated from the ISSR and SRAP data sets was estimated using the $\mathrm{COPH}$ and MXCOP modules in NTSYS-pc (Mantel, 1967). The COPH and MXCOMP programs were used to calculate the goodness of fit between the cluster analysis and the original distance matrix for three data sets (ISSR, SRAP, and ISSR + SRAP).

\section{Results}

Polymorphism analysis. Twenty-five ISSR primers amplified 283 scorable bands, with an average of 11.32 amplified fragments per primer pair (Table 2; Fig. 1). The number of bands ranged from 8 (ISSR827) to 15 (ISSR 850 and ISSR858) bands per primer, with an average of 10.92 bands showing polymorphism. The percentage of PPL of the 25 primers tested ranged from $84.62 \%$ for primer ISSR 895 to $100 \%$ for primers ISSR 808 , ISSR 816 , ISSR 823 , ISSR824, ISSR827, ISSR835, ISSR842, SSR859, ISSR866, and ISSR890 (Table 2). Of the 627 bands amplified by 30 SRAP primer pairs, 576 bands were polymorphic $(91.87 \%)$. Polymorphisms of all loci ranged from a maximum of 100\% (Me03-Em13, Me04-Em10, Me04-Em16, Me05-Em10, Me06-Em16, Me07-Em18, Me16Em09, Me16-Em16, and Me19-Em09) to a minimum of $66.67 \%(\mathrm{Me} 08-\mathrm{Em} 19)$. An average of 20.9 bands was amplified per primer, and 19.2 bands were polymorphic (Table 3; Fig. 2).

Genetic diversity. Genetic variation accessed using ISSR and SRAP markers for all $86 C$. aciculatus accessions are shown in Tables 2 and 4 . The average values for PPL, $H$ e, and $I$ obtained with the ISSR markers were $94 \%$, 0.3 , and 0.29 , respectively. Genetic diversity 
Table 2. Twenty-five primers sequences used for intersimple sequence repeat (ISSR) amplification and number of bands for each primer.

\begin{tabular}{|c|c|c|c|c|c|}
\hline Primer & $\begin{array}{c}\text { Primer } \\
\text { sequence }\left(5^{\prime}-3^{\prime}\right)\end{array}$ & Temp $\left({ }^{\circ} \mathrm{C}\right)$ & $\begin{array}{l}\text { Total no. } \\
\text { of bands }\end{array}$ & $\begin{array}{l}\text { Polymorphic } \\
\text { no. of bands }\end{array}$ & $\begin{array}{l}\text { Percentage of } \\
\text { polymorphism }\end{array}$ \\
\hline ISSR807 & $(\mathrm{AG})_{8} \mathrm{~T}$ & 52 & 12 & 11 & 91.67 \\
\hline ISSR 808 & $(\mathrm{AG})_{8} \mathrm{C}$ & 55 & 12 & 12 & 100 \\
\hline ISSR809 & $(\mathrm{AG})_{8} \mathrm{G}$ & 55 & 10 & 9 & 90 \\
\hline ISSR815 & $(\mathrm{CT})_{8} \mathrm{G}$ & 55 & 10 & 9 & 90 \\
\hline ISSR816 & $(\mathrm{CA})_{8} \mathrm{~T}$ & 52 & 14 & 14 & 100 \\
\hline ISSR823 & $(\mathrm{TC})_{8} \mathrm{C}$ & 55 & 9 & 9 & 100 \\
\hline ISSR824 & $(\mathrm{TC})_{8} \mathrm{G}$ & 55 & 12 & 12 & 100 \\
\hline ISSR 827 & $(\mathrm{AC})_{8} \mathrm{G}$ & 55 & 8 & 8 & 100 \\
\hline ISSR829 & $(\mathrm{TG})_{8} \mathrm{C}$ & 55 & 10 & 9 & 90 \\
\hline ISSR834 & $(\mathrm{AG})_{8} \mathrm{YT}$ & 54 & 10 & 9 & 90 \\
\hline ISSR835 & $(\mathrm{AG})_{8} \mathrm{YC}$ & 56 & 10 & 10 & 100 \\
\hline ISSR841 & $(\mathrm{GA})_{8} \mathrm{YC}$ & 56 & 13 & 12 & 92.31 \\
\hline ISSR 842 & $(\mathrm{GA})_{8} \mathrm{YG}$ & 56 & 10 & 10 & 100 \\
\hline ISSR 848 & $(\mathrm{CA})_{8} \mathrm{RG}$ & 56 & 10 & 9 & 90 \\
\hline ISSR849 & $(\mathrm{GT})_{8} \mathrm{YA}$ & 54 & 10 & 9 & 90 \\
\hline ISSR 850 & $(\mathrm{GT})_{8} \mathrm{YC}$ & 56 & 15 & 14 & 93.33 \\
\hline ISSR 855 & $(\mathrm{AC})_{8} \mathrm{YT}$ & 54 & 10 & 9 & 90 \\
\hline ISSR857 & $(\mathrm{AC})_{8} \mathrm{YG}$ & 56 & 10 & 9 & 90 \\
\hline ISSR858 & $(\mathrm{TG})_{8} \mathrm{RT}$ & 54 & 15 & 13 & 86.67 \\
\hline ISSR859 & $(\mathrm{TG})_{8} \mathrm{RC}$ & 56 & 10 & 10 & 100 \\
\hline ISSR866 & $(\mathrm{CTC})_{6}$ & 61 & 12 & 12 & 100 \\
\hline ISSR 880 & $(\text { GGAGA })_{3}$ & 60 & 13 & 12 & 92.31 \\
\hline ISSR 890 & $\operatorname{VHV}(\mathrm{GT})_{7}$ & 54 & 12 & 12 & 100 \\
\hline ISSR891 & $\mathrm{HVH}(\mathrm{TG})_{7}$ & 53 & 13 & 12 & 92.31 \\
\hline ISSR895 & $\begin{array}{l}(\mathrm{AG})_{2} \text { TTGGT } \\
\quad \mathrm{AG}(\mathrm{CT})_{2} \text { TGATC }\end{array}$ & 56 & 13 & 11 & 84.62 \\
\hline $\begin{array}{l}\text { Total } \\
\text { Average }\end{array}$ & & & $\begin{array}{l}283 \\
11.32\end{array}$ & $\begin{array}{l}266 \\
10.64\end{array}$ & 94 \\
\hline
\end{tabular}

Table 3. Forward and reverse sequence-related amplified polymorphism primers used in this study.

\begin{tabular}{llll}
\hline Codes & Forward primers $\left(5^{\prime}-3^{\prime}\right)$ & Codes & Reverse primers $\left(5^{\prime}{ }^{\prime}{ }^{\prime}\right)$ \\
\hline $\mathrm{Me} 01$ & TGAGTCCAAACCGGATA & Em01 & GACTGCGTACGAATTCAA \\
$\mathrm{Me} 02$ & TGAGTCCAAACCGGAGC & Em02 & GACTGCGTACGAATTCTG \\
$\mathrm{Me} 03$ & TGAGTCCAAACCGGACC & Em03 & GACTGCGTACGAATTGAC \\
$\mathrm{Me} 04$ & TGAGTCCAAACCGGACA & Em04 & GACTGCGTACGAATTTGA \\
$\mathrm{Me} 05$ & TGAGTCCAAACCGGTGC & Em05 & GACTGCGTACGAATTAAC \\
$\mathrm{Me} 06$ & TGAGTCCAAACCGGAGA & Em06 & GACTGCGTACGAATTGCA \\
$\mathrm{Me} 07$ & TGAGTCCAAACCGGACG & Em07 & GACTGCGTACGAATTGAG \\
$\mathrm{Me} 08$ & TGAGTCCAAACCGGAAA & Em08 & GACTGCGTACGAATTGCC \\
$\mathrm{Me} 09$ & TGAGTCCAAACCGGAAC- & Em09 & GACTGCGTACGAATTTCA \\
$\mathrm{Me} 10$ & TGAGTCCAAACCGGAAT & Em10 & GACTGCGTACGAATTCAT \\
$\mathrm{Me} 11$ & TGAGTCCAAACCGGAAG & Em11 & GACTGCGTACGAATTAAT \\
$\mathrm{Me} 12$ & TGAGTCCAAACCGGTAG & Em12 & GACTGCGTACGAATTTGC \\
$\mathrm{Me} 13$ & TGAGTCCAAACCGGTTG & Em13 & GACTGCGTACGAATTCGA \\
$\mathrm{Me} 14$ & TGAGTCCAAACCGGTGT & Em14 & GACTGCGTACGAATTATG \\
$\mathrm{Me} 15$ & TGAGTCCAAACCGGTCA & Em15 & GACTGCGTACGAATTAGC \\
$\mathrm{Me} 16$ & TGAGTCCAAACCGGGAC & Em16 & GACTGCGTACGAATTACG \\
$\mathrm{Me} 17$ & TGAGTCCAAACCGGGTA & Em17 & GACTGCGTACGAATTTAG \\
$\mathrm{Me} 18$ & TGAGTCCAAACCGGGGT & Em18 & GACTGCGTACGAATTCG \\
$\mathrm{Me} 19$ & TGAGTCCAAACCGGCAG & Em19 & GACTGCGTACGAATTGTC \\
$\mathrm{Me} 20$ & TGAGTCCAAACCGGCAT & Em20 & GACTGCGTACGAATTGGT \\
\hline
\end{tabular}

identified using the SRAP markers was similar to that of the ISSR markers, as indicated by the average values for PPL, $\mathrm{He}$, and $I$ of $91.87 \%, 0.29$, and 0.26 , respectively. The genetic similarity coefficients (GSCs) calculated using the UPGMA clustering method based on ISSR polymorphism ranged from 0.52 to 0.93 . Accessions from the same geographic location (CA01 and CA10) in Haikou, Hainan Province, showed a GSC of 0.93 . The GSC values derived from the SRAP data set ranged from 0.56 to 0.91 . The largest GSC was between accessions CA21 (Dingan, Hainan Province) and CA24 (Sanya, Hainan Province). These results suggested that a high level of genetic diversity was exhibited among all samples.

Cluster analysis. A UPGMA dendrogram derived from the ISSR data were generated to explore the genetic relationships among the 86 accessions. The accessions were divided into three main clusters (I, II, and III) (Fig. 3). Cluster I comprised of 19 samples from Hainan (18) and Guangxi (1) provinces. Cluster II included 54 accessions, which were further divided into two subclusters: subcluster II-1 contained eight accessions from Hainan (1), Guangxi (3), Guangdong (2), Fujian (1), and Yunnan (1) provinces; and subcluster II-2 contained 36 accessions from Guangxi (18), Hainan (12), Guangdong (4), and Fujian (2) provinces. Cluster III comprised 14 samples from Hainan (8), Yunnan (3), Guangdong (2), and Guangxi (1) provinces. Accessions from the same region were generally grouped within the same cluster.

The dendrogram (Fig. 4) derived from the SRAP data grouped the 86 accessions into three main clusters (IV, V, and VI). Cluster V was divided into two subgroups, V-1 and V-2. Cluster IV was similar to cluster III. Cluster V was similar to cluster II, and cluster VI was similar to cluster I. CA04 was placed in cluster $\mathrm{I}$, and CA22 and CA23 were grouped in cluster II in the ISSR analysis; in contrast, CA04, CA22, and CA23 were assigned to cluster IV in the SRAP analysis.

In addition, a dendrogram derived from a combined ISSR and SSR data set was constructed, for which the GSCs ranged from 0.56 to 0.88 (Fig. 5). In the combined data analysis, the 86 accessions were classified into four major clusters (VII, VIII, IX, and $\mathrm{X})$. The groups were similar to those obtained in the ISSR analysis. Cluster I was similar to cluster X, except that CA01, CA04, CA06, CA07, and CA10 placed in cluster I based on the ISSR data (Fig. 3) were grouped in cluster VII (Fig. 5). CA20, CA22, CA23, and CA27 placed in subcluster II-1 (Fig. 3) were grouped in cluster X (Fig. 5). The accessions placed in subcluster II-2 and cluster III were identical to those grouped in clusters VIII and IX, respectively.

\section{Discussion}

Previous studies demonstrate that ISSR and SRAP markers are valuable for markerassisted selection, analysis of genetic diversity, and population genetic analysis (Budak et al., 2004a, 2004b, 2004c; Carvalho et al., 2009; Gupta and Varshney, 2000). Both marker types have been successfully used for genetic analyses of warm-season turfgrasses, such as Zoysia japonica Steud. (Chen et al., 2009; Xie et al., 2012), Cynodon dactylon (Huang et al., 2010; Li et al., 2011; Ling et al., 2010; Wang et al., 2009b, 2013; Yi et al., 2008), Cynodon arcuatus J. Presl (Huang et al., 2013), and Eremochloa ophiuroides (Munro) Hack. (Zheng et al., 2009, 2013). The present study is the first assessment of the molecular genetic diversity among $C$. aciculatus accessions using ISSR and SRAP markers.

Evaluation of genetic diversity among a sample of accessions provides an important foundation for conservation of genetic resources and marker-assisted breeding. In the present study, ISSR and SRAP data revealed high genetic diversity among the 86 C. aciculatus accessions. The 25 ISSR markers yielded a higher PPL (94\%) than the 30 SRAP markers $(91.87 \%)$. The values of $\mathrm{He}$ and $I$ generated by the ISSR markers $(0.3$ and 0.29 , respectively) were slightly higher than those generated using SRAP markers ( 0.29 and 0.26 , respectively), which indicated that ISSR markers provided more informative data than SRAP markers. Differences in the results obtained with the ISSR and SRAP markers probably reflect the different genomic regions amplified by the two marker types. Similar results were obtained for Auricularia auricula-judae Quel. (Tang et al., 2010), Pogostemon cablin Benth. (Wu et al., 2010), and Prunella vulgaris L. (Liao et al., 2012) using ISSR and SRAP molecular markers. 
Table 4. Amplification results of 30 sequence-related amplified polymorphism primer combinations used in this study.

\begin{tabular}{|c|c|c|c|}
\hline Primer combinations & $\begin{array}{c}\text { Total no. } \\
\text { of polymorphic }\end{array}$ & $\begin{array}{c}\text { No. of } \\
\text { polymorphic bands }\end{array}$ & $\begin{array}{c}\text { Percentage of } \\
\text { polymorphic bands }\end{array}$ \\
\hline$\overline{\mathrm{Me} 02-\mathrm{Em} 13}$ & 18 & 16 & 88.89 \\
\hline Me03-Em13 & 18 & 18 & 100 \\
\hline Me03-Em17 & 17 & 16 & 94.11 \\
\hline Me03-Em19 & 18 & 16 & 88.89 \\
\hline $\mathrm{Me} 04-\mathrm{Em} 04$ & 22 & 21 & 95.45 \\
\hline $\mathrm{Me} 04-\mathrm{Em} 10$ & 23 & 23 & 100 \\
\hline $\mathrm{Me} 04-\mathrm{Em} 13$ & 17 & 15 & 88.24 \\
\hline $\mathrm{Me} 04-\mathrm{Em} 16$ & 23 & 23 & 100 \\
\hline $\mathrm{Me} 05-\mathrm{Em} 10$ & 23 & 23 & 100 \\
\hline $\mathrm{Me} 05-\mathrm{Em} 19$ & 23 & 18 & 78.26 \\
\hline $\mathrm{Me} 06-\mathrm{Em} 16$ & 21 & 21 & 100 \\
\hline Me07-Em09 & 15 & 11 & 73.33 \\
\hline Me07-Em18 & 18 & 18 & 100 \\
\hline Me08-Em19 & 15 & 10 & 66.67 \\
\hline Me09-Em15 & 25 & 23 & 92 \\
\hline Me09-Em16 & 22 & 20 & 90.9 \\
\hline Me10-Em04 & 25 & 23 & 92 \\
\hline Me10-Em06 & 26 & 24 & 92.31 \\
\hline Me11-Em06 & 27 & 22 & 81.48 \\
\hline Me12-Em19 & 25 & 23 & 92 \\
\hline Me13-Em19 & 24 & 23 & 95.83 \\
\hline Me14-Em16 & 24 & 23 & 95.83 \\
\hline Me16-Em06 & 24 & 20 & 83.33 \\
\hline Me16-Em09 & 23 & 23 & 100 \\
\hline Me16-Em16 & 18 & 18 & 100 \\
\hline Me17-Em18 & 23 & 22 & 95.65 \\
\hline Me19-Em09 & 12 & 12 & 100 \\
\hline Me19-Em17 & 25 & 19 & 73.08 \\
\hline Me19-Em19 & 22 & 18 & 81.82 \\
\hline Me20-Em17 & 15 & 14 & 93.33 \\
\hline Total & 627 & 576 & 91.87 \\
\hline Average & 20.9 & 19.2 & \\
\hline
\end{tabular}

The Mantel matrix correspondence test was used for an overall comparison of matrices of cophenetic values produced from dissimilarity matrices generated in the UPGMA cluster analysis (Mantel, 1967). The Mantel's test indicated that the ISSR and SRAP cophenetic values were significantly correlated $(r=0.8023)$, thus the ISSR and SRAP markers revealed similar patterns of genetic diversity in $C$. aciculatus accurately.

The dendrograms generated from the ISSR and SRAP data sets showed strong similarity in topology. Accessions with the same provenance were generally clustered in the same group. Accessions from the same geographical area that were clustered into different groups may reflect gene flow from introduced species or introgression ( $\mathrm{Li}$ et al., 2011). Conversely, accessions from different regions that clustered together may be explained by the outcrossing breeding system of $C$. aciculatus or by exchange of germplasm resources between regions (Farsani et al., 2012). Genetic overlap occurs in neighboring regions ( $\mathrm{Li}$ et al., 2011; Yi et al., 2008). In the present study, the $86 C$. aciculatus accessions originated from five provinces, of which Fujian, Guangdong, Guangxi, and Yunnan provinces are adjacent to each other. C. aciculatus shows strong vegetative reproduction, and human activities may have aided dispersal, with subsequent vegetative spread and sexual reproduction leading to a high level of genetic diversity.

In this study, we combined the ISSR and SRAP data sets to examine the degree of agreement between the individual marker types. Although combining data remains controversial (Mohammadi and Prasanna, 2003), combining the ISSR and SRAP data sets allowed a more comprehensive analysis of genetic diversity and provided greater information for future marker-assisted selection in the breeding of C. aciculatus. The 86 C. aciculatus accessions were clustered into four groups based on the combined data sets. The clusters generally reflected the geographical distribution of the accessions, similar to that based on separate analyses of the ISSR and SRAP data sets. In addition, we measured five indices of plant growth, namely chlorophyll content, maximum leaf length, withering rate, quality evaluation, and quality of dry matter, with the aim of assessing the shade tolerance of C. aciculatus. A clustering analysis diagram was generated based on the growth parameter data (X.Y. Zhang, Z.Y. Wang, and L. Liao, unpublished data). From these two cluster analyses, it was determined that cluster VII is characterized by excellent shade tolerance. The growth parameters of clusters VIII and IX are generally intermediate to those of clusters I and X, with the growth parameters of cluster IX slightly lower than those of cluster VIII. Accessions grouped in cluster X showed opposing characteristics to those of cluster VII. Accessions placed in clusters VII and VIII may prove useful turfgrasses for planting. Thus, the information provided by the combined marker analysis may prove useful for selection of parents in the breeding of improved shade-tolerant accessions of C. aciculatus.
In conclusion, this study assessed molecular genetic diversity and relationships among 86 C. aciculatus accessions using ISSR and SRAP markers. Both ISSR and SRAP markers are reliable and effective tools for analysis of genetic diversity in $C$. aciculatus, with high levels of genetic diversity detected among the 86 populations sampled. ISSR markers show a higher PPL (94\%) than SRAP markers $(91.87 \%)$. Cluster analysis of the ISSR and SRAP data independently yielded similar results. The $C$. aciculatus accessions were clustered into three groups. The clusters were generally consistent with the geographic provenances of the accessions. Cluster analysis of the combined ISSR and SRAP data sets generated similar groupings to those derived from separate analyses of the ISSR and SRAP data sets. Indices of shade tolerance differ among each group of accessions. Thus, ISSR and SRAP markers are informative for evaluation of genetic diversity in C. aciculatus, and may be useful in the conservation of genetic resources, development of biodiversity conservation strategies, and identification of wild germplasm resources. The markers may also contribute to future molecular marker-assisted breeding programs.

\section{Literature Cited}

Babaei, S., M. Talebi, M. Bahar, and H. Zeinali. 2014. Analysis of genetic diversity among saffron (Crocus sativus) accessions from different regions of Iran as revealed by SRAP markers. Sci. Hort. 171:27-31.

Baliyan, D., A. Sirohi, M. Kumar, V. Kumar, S. Malik, S. Sharma, and S. Sharma. 2014. Comparative genetic diversity analysis in chrysanthemum: A pilot study based on morpho-agronomic traits and ISSR markers. Sci. Hort. 167:164-168.

Barth, S., A.E. Melchinger, and T. Lübberstedt. 2002. Genetic diversity in Arabidopsis thaliana L. Heynh. investigated by cleaved amplified polymorphic sequence (CAPS) and intersimple sequence repeat (ISSR) markers. Mol. Ecol. 11: 495-505.

Biswas, M.K., Q. Xu, and X.X. Deng. 2010. Utility of RAPD, ISSR, IRAP and REMAP markers for the genetic analysis of Citrus spp. Sci. Hort. 124:254-261.

Budak, H., R.C. Shearman, I. Parmaksiz, and I. Dweikat. 2004a. Comparative analysis of seeded and vegetative biotype buffalograsses based on phylogenetic relationship using ISSRs, SSRs, RAPDs, and SRAPs. Theor. Appl. Genet. 109: 280-288.

Budak, H., R.C. Shearman, I. Parmaksiz, R.E. Gaussoin, R.E. Gaussoin, T.P. Riordan, and I. Dweikat. 2004b. Molecular characterization of buffalograss germplasm using sequence-related amplified polymorphism markers. Theor. Appl. Genet. 108:328-334.

Budak, H., R.C. Shearman, I. Parmaksiz, R.E. Gaussoin, T.P. Riordan, and I. Dweikat. 2004c. Application of sequence-related amplified polymorphism markers for characterization of turfgrass species. Hortic. Sci. (Prague) 39:955-958.

Cai, X., Z. Feng, X. Zhang, W. Xu, B. Hou, and X. Ding. 2011. Genetic diversity and population structure of an endangered Orchid (Dendrobium loddigesii Rolfe) from China revealed by SRAP markers. Sci. Hort. 129:877-881.

Carvalho, A., J. Lima-Brito, B. Maçãs, and H. GuedesPinto. 2009. Genetic diversity and variation among botanical varieties of old Portuguese wheat 

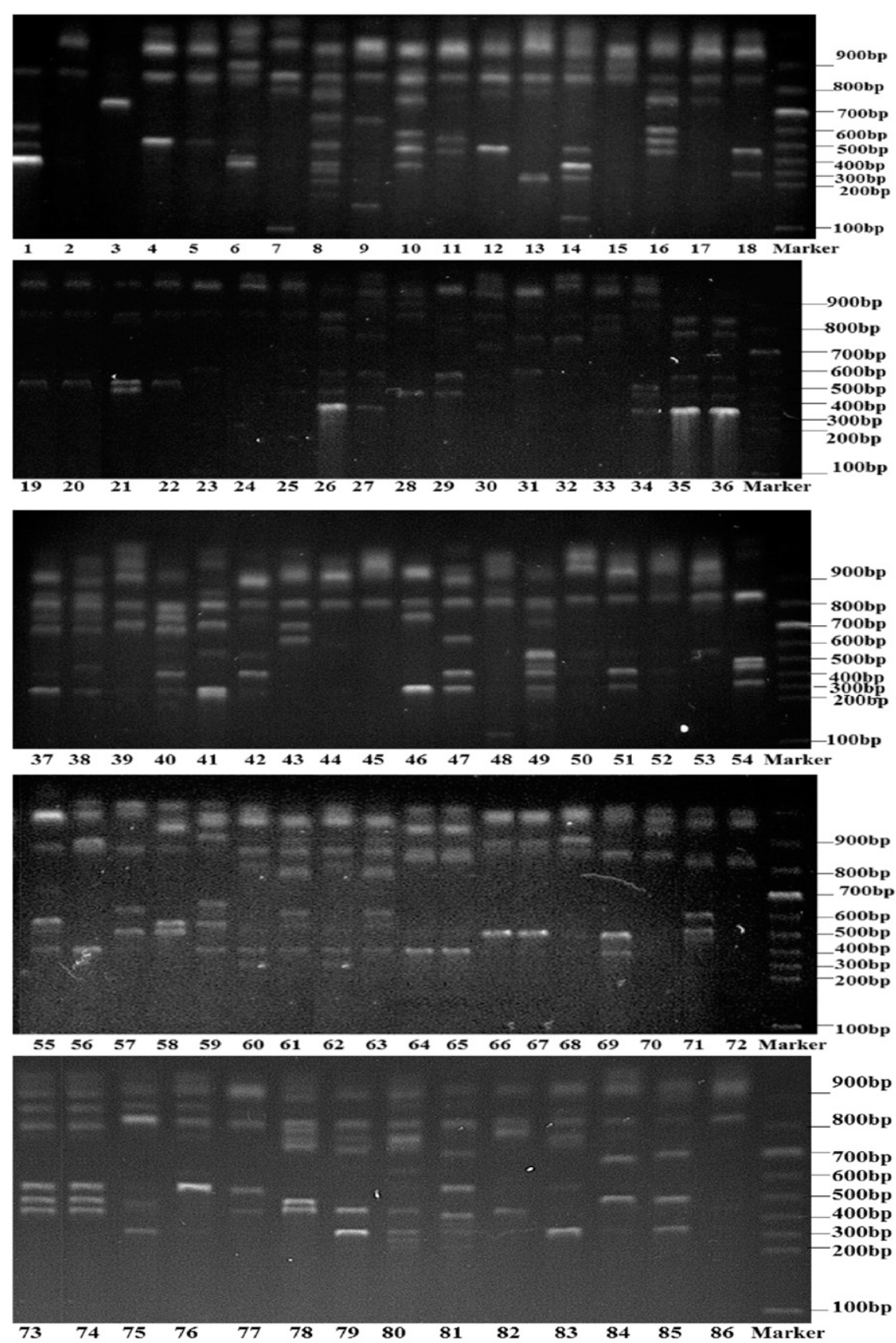

Fig. 1. Intersimple sequence repeat amplified with primer ISSR842 in 86 Chrysopogon aciculatus DNA of C. aciculatus samples. The size standard is a 100-bp DNA ladder and the sample number is shown in Table 1 . cultivars revealed by ISSR assays. Biochem. Genet. 47:276-294.

Chen, X., H.L. Guo, D.D. Xue, Y.Q. Zheng, and J.X. Liu. 2009. Identification of SRAP molecular markers linked to salt tolerance in Zoysia grasses. Acta Pratac. Sin. 18: 66-75.

Clarkson, B.D. 1992. Manual of flowering plants of Hawaii. N.Z. J. Bot. 30:119-120.

Djè, Y., C.G. Tahi, A.I.Z. Bi, J.P. Baudoin, and P. Bertin. 2010. Use of ISSR markers to assess genetic diversity of African edible seeded Citrullus lanatus landraces. Sci. Hort. 124:159-164.

Doyle, J.J. and J.L. Doyle. 1987. A rapid DNA isolation procedure for small quantities of fresh leaf tissue. Phytochem. Bull. 19:11-15.

Farsani, T.M., N. Etemadi, B.E. Sayed-Tabatabaei, and M. Talebi. 2012. Assessment of genetic diversity of bermudagrass (Cynodon dactylon) of plant diversity with retrotransposon-based molecular markers. Heredity 106:520-530.

Kalia, R.K., M.K. Rai, S. Kalia, R. Singh, and A.K. Dhawan. 2011. Microsatellite markers: An overview of the recent progress in plants. Euphytica 177:309-334.

Kalpana, D., H.C. Si, T.K. Choi, K. Senthil, and S.L. Yang. 2012. Assessment of genetic diversity among varieties of mulberry using RAPD and ISSR fingerprinting. Sci. Hort. 134:79-89.

Li, H., L. Liu, Y. Lou, T. Hu, and J. Fu. 2011 Genetic diversity of Chinese natural bermudagrass (Cynodon dactylon) germplasm using ISSR markers. Sci. Hort. 127:555-561.

Li, G. and C.F. Quiros. 2001. Sequence-related amplified polymorphism (SRAP), a new marker system based on a simple PCR reaction: Its application to mapping and gene tagging in Brassica. Theor. Appl. Genet. 103:455-461.

Li, M., Z. Zhao, and X. Miao. 2014. Genetic diversity and relationships of apricot cultivars in North China revealed by ISSR and SRAP markers. Sci. Hort. 173:20-28.

Liao, L., C.J. Bai, X.L. Guo, and Z.Y. Wang. 2011. Morphological diversity of Chrysopogon aciculatus. Chin. J. Trop. Crops 32:2042-2047.

Liao, L., Q.S. Guo, Z.Y. Wang, L. Liu, and Z.B. Zhu. 2012. Genetic diversity analysis of Prunella vulgaris in China using ISSR and SRAP markers. Biochem. Syst. Ecol. 45: 209-217.

Ling, Y., X.Q. Zhang, X.F. Qi, Y.J. Zhou, W. Liu, X. Ma, and S.Y. Chen. 2010. Genetic diversity of wild Cynodon dactylon germplasm from five province of Southwest China and Africa detected by SRAP markers. Acta Pratac. Sin. 19 196-203.

Liu, L.W., L.P. Zhao, Y.Q. Gong, M.X. Wang, L.M. Chen, J.L. Yang, Y. Wang, F.M. Yu, and L.Z. Wang. 2008. DNA fingerprinting and genetic diversity analysis of late-bolting radish cultivars with RAPD, ISSR and SRAP markers. Sci. Hort. 116:240-247.

Mantel, N.A. 1967. The detection of disease clustering and a generalized regression approach. Cancer Res. 27:209-220.

Mohammadi, S.A. and B.M. Prasanna. 2003. Analysis of genetic diversity in crop plants-salient statistical tools and considerations. Crop Sci. 43:1235-1248

Nei, M. 1973. Analysis of gene diversity in subdivided populations. Proc. Natl. Acad. Sci. USA 70:3321-3323

Nei, M. and W.H. Li. 1979. Mathematical model for studying genetic variation in terms of restriction endonucleases. Proc. Natl. Acad. Sci. USA 76:5269-5273.

Reunova, G.D., I.L. Kats, T.I. Muzarok, and Y.N Zhuravlev. 2010. Polymorphism of RAPD, ISSR and AFLP markers of the Panax ginseng C.A. Meyer (Araliaceae) genome. Russ. J. Genet. 46:938-947.

using ISSR markers. Intl. J. Mol. Sci. 13:383392.

Gupta, P.K. and R.K. Varshney. 2000. The development and use of microsatellite markers for genetic analysis and plant breeding with emphasis on bread wheat. Euphytica 113 163-185.

Huang, C.Q., G.D. Liu, C.J. Bai, and W.Q. Wang 2013. Genetic relationships of Cynodon arcuatus from different regions of China revealed by ISSR and SRAP markers. Sci. Hort. 162:172-180.

Huang, C.Q., G.D. Liu, C.J. Bai, W.Q. Wang, S.Y. Zhou, and D.Q. Yu. 2010. Estimation of genetic variation in Cynodon dactylon accessions using the ISSR technique. Biochem. Syst. Ecol. 38: 463-470.

Kalendar, R., A.J. Flavell, T.H.N. Ellis, T. Sjakste, C. Moisy, and A.H. Schulman. 2011. Analysis

Shannon, C.E. and W. Weaver. 1949. The mathematical theory of communication. University of Illinois Press, Chicago, IL.

Smolik, M., I. Ochmian, and J. Grajkowski. 2010. Genetic variability of Polish and Russian accessions of cultivated blue honeysuckle (Lonicera caerulea). Russ. J. Genet. 46:1079-1085.

Sneath, P.H.A. and R.R. Sokal. 1973. Numerical taxonomy. Freeman, San Francisco, CA.

Song, Z., X. Li, H. Wang, and J. Wang. 2010. Genetic diversity and population structure of Salvia miltiorrhiza Bge in China revealed by ISSR and SRAP. Genetica 138:241-249.

Tang, L., X. Yang, L. Li, G. Qian, and Y. Bian. 2010. Analysis of genetic diversity among Chinese Auricularia auricula cultivars using combined 


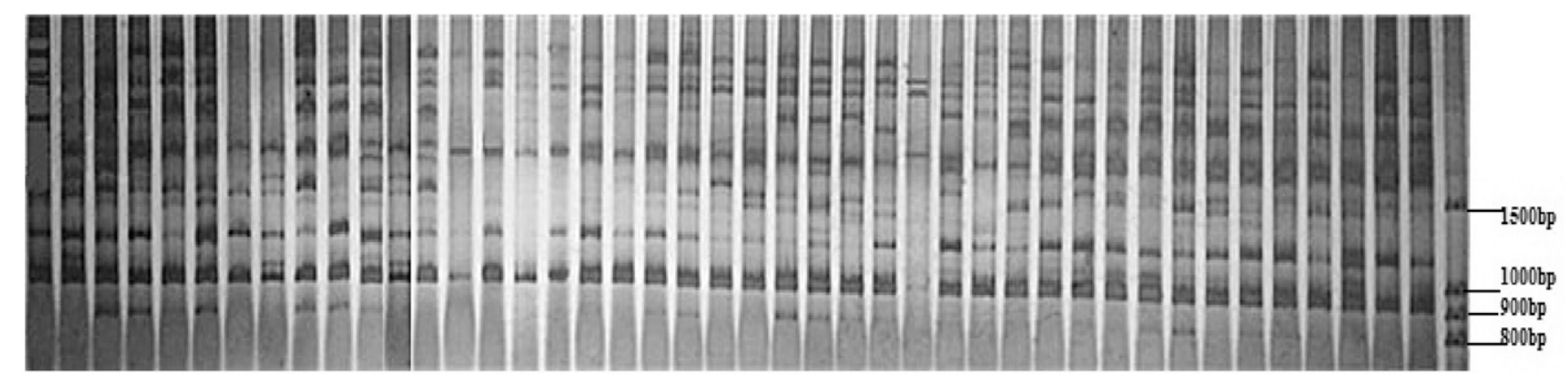

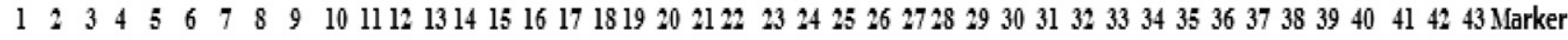

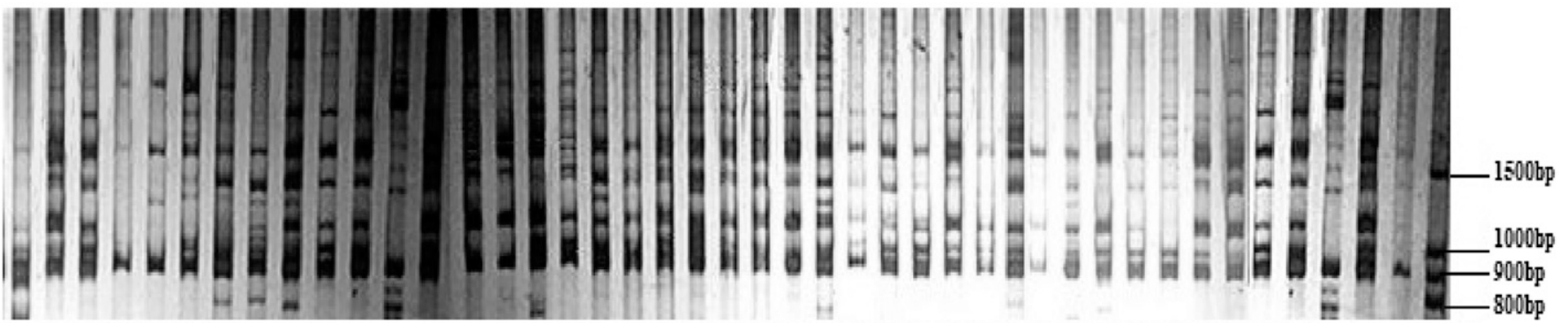

$444546474849505152535455 \quad 56 \quad 5758596061 \quad 6263646566676869707172737475767778798081828384 \quad 8586$ Marker

Fig. 2. Sequence-related amplified polymorphism amplified with primer combination Me19-Em09 in 86 Chrysopogon aciculatus DNA of C. aciculatus samples. The size standard is 100-bp DNA ladder and the sample number is shown in Table 1.

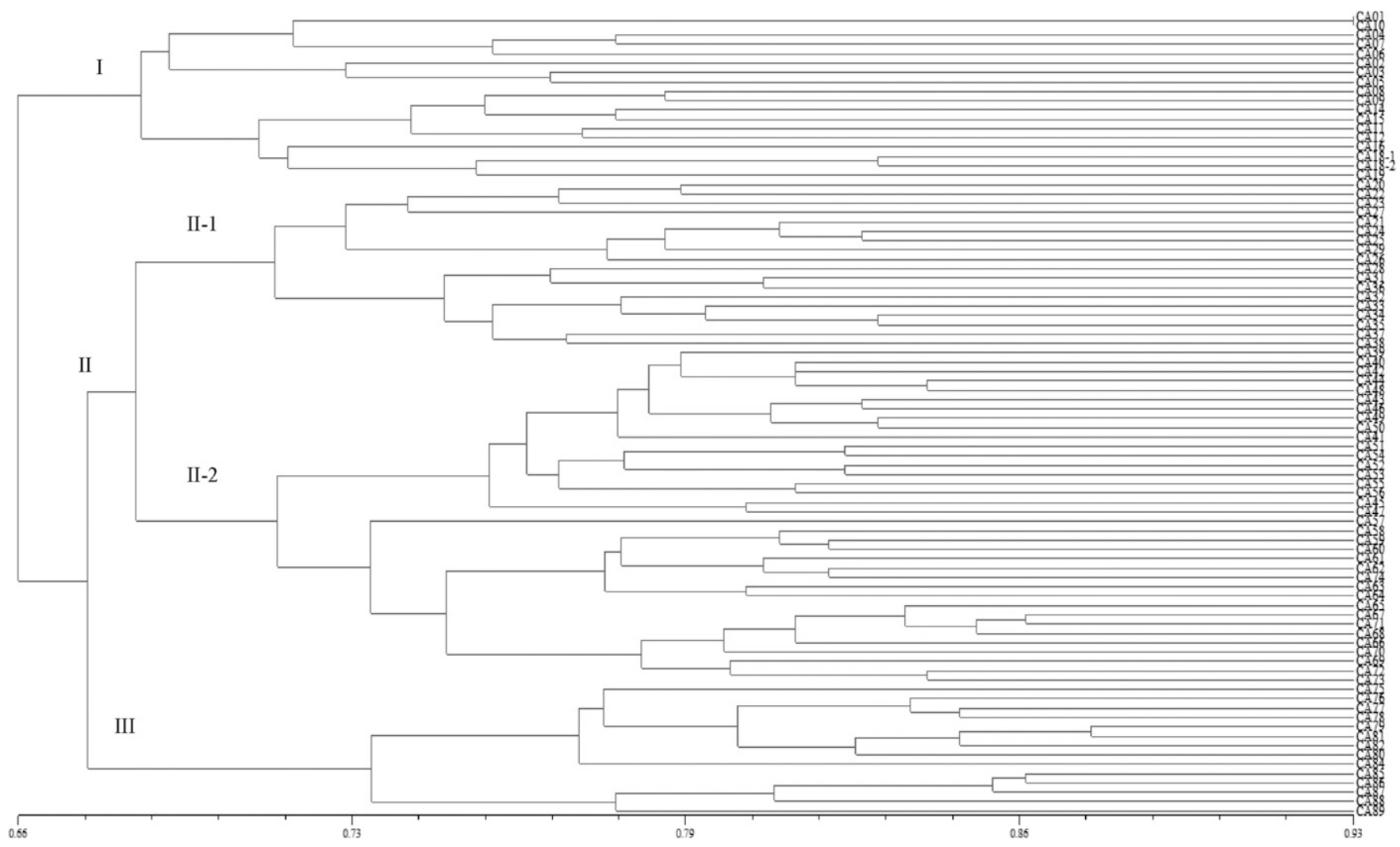

Fig. 3. Unweighted pair-group method with arithmetic averages clustering for 86 Chrysopogon aciculatus accessions based on intersimple sequence repeat markers.

ISSR and SRAP markers. Curr. Microbiol. 61: $132-140$.

Tao, J., G. Qiao, X.P. Wen, G.L. Gao, T. Liu, Z.J. Peng, Y.Q. Cai, N. Chen, F.X. Yan, and B.X. Zhang. 2014. Characterization of genetic relationship of dragon fruit accessions (Hylocereus spp.) by morphological traits and ISSR markers. Sci. Hort. 170:82-88.

Uzun, A., T. Yesiloglu, Y. Aka-Kacar, O. Tuzcu, and O. Gulsen. 2009. Genetic diversity and population structure within Citrus and related genera based on sequence related amplified polymorphism markers (SRAPs). Sci. Hort. 121:306-312.

Wang, Z., L. Liao, X. Yuan, H. Guo, A. Guo, and J. Liu. 2013. Genetic diversity analysis of Cynodon dactylon (bermudagrass) accessions and cultivars from different countries based on ISSR 


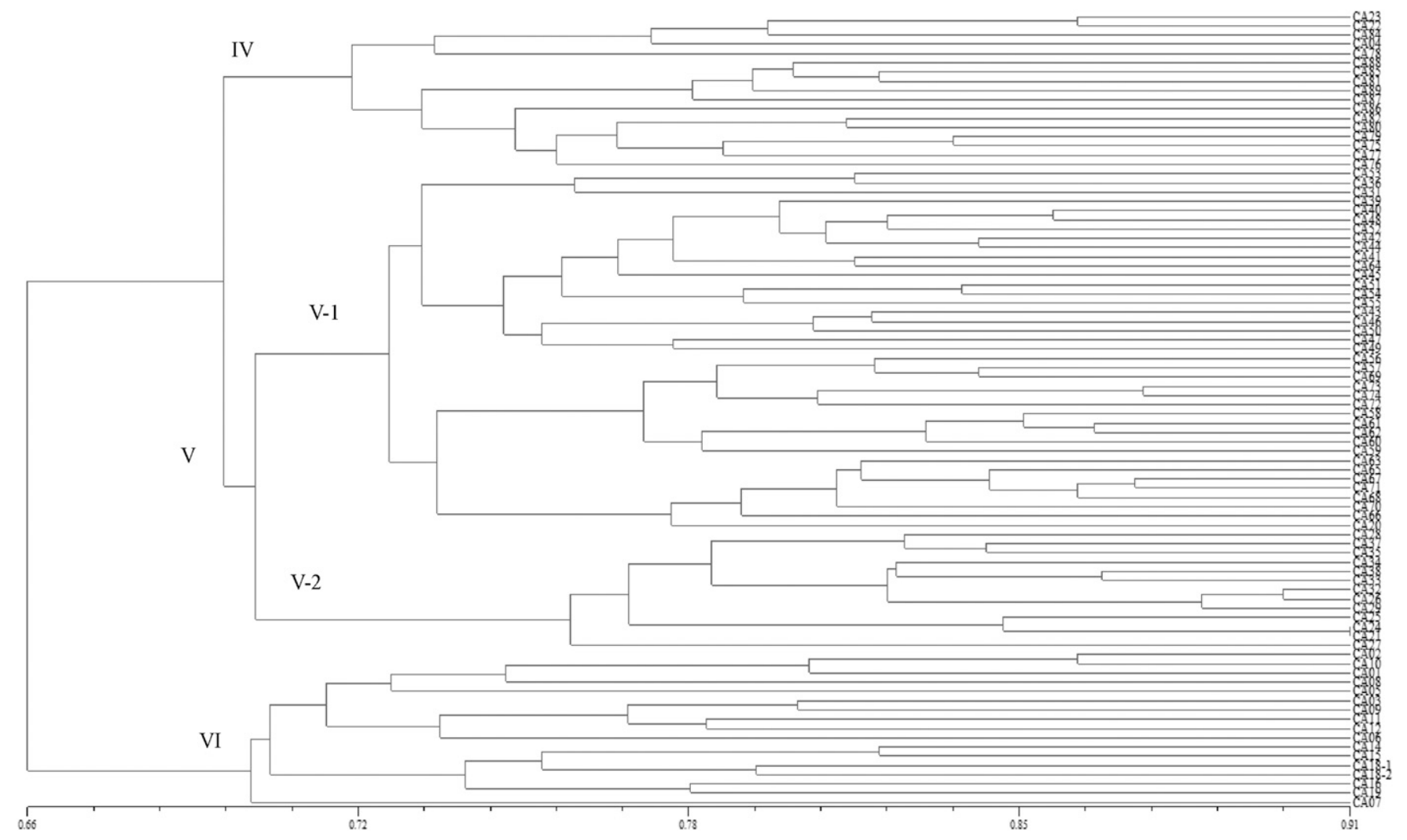

Fig. 4. Unweighted pair-group method with arithmetic averages dendrogram based on sequence-related amplified polymorphism data of 86 Chrysopogon aciculatus accessions.

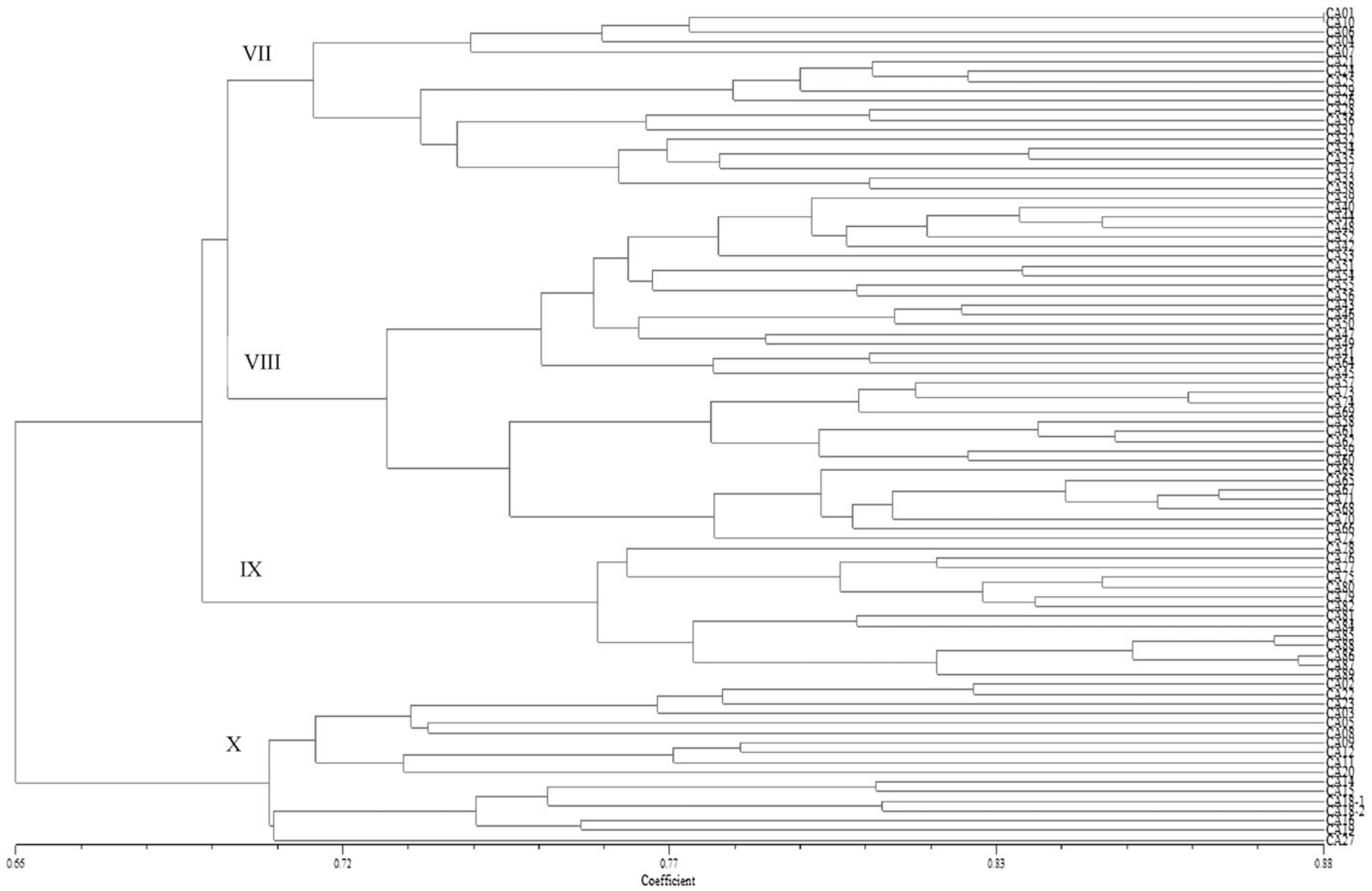

Fig. 5. Unweighted pair-group method with arithmetic averages cluster for 86 Chrysopogon aciculatus accessions based on intersimple sequence repeat and sequence-related amplified polymorphism markers. 
and SSR markers. Biochem. Syst. Ecol. 46:108-115.

Wang, Z.Y., X.J. Yuan, H.L. Guo, X.L. Liu, and Z.F. Zhou. 2009a. Optimization of ISSR-PCR system on Zoysia spp. Acta Pratacult. Sin. 17: $48-51$.

Wang, Z., X. Yuan, Y. Zheng, and J. Liu. 2009b. Molecular identification and genetic analysis for 24 turf-type Cynodon cultivars by sequencerelated amplified polymorphism markers. Sci. Hort. 122:461-467.

Wu, Y.G., Q.S. Guo, J.C. He, Y.F. Lin, L.J. Luo, and G.D. Liu. 2010. Genetic diversity analysis among and within populations of Pogostemon cablin from China with ISSR and SRAP markers. Biochem. Syst. Ecol. 38:63-72.

Xie, Y., L. Liu, J. Fu, and H. Li. 2012. Genetic diversity in Chinese natural zoysiagrass based on inter-simple sequence repeat (ISSR) analysis. Afr. J. Biotechnol. 11:7659-7669.

Yi, Y.J., X.Q. Zhang, L.K. Huang, Y. Ling, and M.A. Xiao. 2008. Genetic diversity of wild Cynodon dactylon germplasm detected by SRAP markers. Hereditas 30:94-100.

Yildiz, M., E. Ekbic, D. Keles, S. Sensoy, and K. Abak. 2011. Use of ISSR, SRAP, and RAPD markers to assess genetic diversity in Turkish melons. Sci. Hort. 130:349-353.

Yilmaz, K.U., S. Paydas-Kargi, Y. Dogan, and S. Kafkas. 2012. Genetic diversity analysis based on ISSR, RAPD and SSR among Turkish Apricot Germplasms in Iran Caucasian ecogeographical group. Sci. Hort. 138:138-143.

Zheng, Y., H. Guo, G. Zang, and J. Liu. 2013. Genetic linkage maps of centipedegrass [Eremochloa ophiuroides (Munro) Hack.] based on sequence-related amplified polymorphism and expressed sequence tag-simple sequence repeat markers. Sci. Hort. 156:86-92.

Zheng, Y.Z., J.B. Xi, and Z.Y. Yang. 2005. Studies on distribution and morphological variation of wild grass Chrysopogon aciculatus collected from the tropics and subtropics of China. Acta Agrestia Sin. 13:117-122.

Zheng, Y.Q., J.Q. Zong, D.D. Xue, X. Chen, and J.X. Liu. 2009. Application of SRAP markers to the identification of Eremochloa ophiuroides (Munro) Hack hybrids. Acta Agrestia Sin. 17: 135-140.

Zietkiewicz, E., A. Rafalski, and D. Labuda. 1994. Genome fingerprinting by simple sequence repeat (SSR)-anchored polymerase chain reaction amplification. Genomics 20: 176-183. 